\title{
TP53 Mutations and S-Phase Fraction but not DNA-Ploidy Are Independent Prognostic Indicators in Laryngeal Squamous Cell Carcinoma
}

\author{
ANTONIO RUSSO,${ }^{1} *$ SIMONA CORSALE, ${ }^{2}$ VALENTINA AGNESE, ${ }^{1}$ MARCELLA MACALUSO,${ }^{1,3}$ \\ SANDRA CASCIO,${ }^{1,3}$ LOREDANA BRUNO ${ }^{1}$ EVA SURMACZ, ${ }^{3}$ GABRIELLA DARDANONI ${ }^{4}$ \\ MARIA ROSARIA VALERIO, ${ }^{1}$ SALVATORE VIENI, ${ }^{1}$ SALVATORE RESTIVO, ${ }^{5}$ FABIO FULFARO, ${ }^{1}$ \\ ROSA MARIA TOMASINO, ${ }^{\mathbf{6}}$ NICOLA GEBBIA, ${ }^{\mathbf{1}}$ AND VIVIANA BAZAN ${ }^{\mathbf{1}}$ \\ ${ }^{1}$ Section and Oncology, Department of Oncology, Università di Palermo, Palermo, Italy \\ ${ }^{2}$ Institute of Experimental Medicine, Università di Palermo, Palermo, Italy \\ ${ }^{3}$ Sbarro Institute for Cancer Research and Molecular Medicine, College of Science \\ and Technology, Temple University, Philadelphia, Pennsylvania \\ ${ }^{4}$ Epidemiological Observatory Center of Sicilian Region, Palermo, Italy \\ ${ }^{5}$ Institute of Otorhinolaryngology B, Università di Palermo, Palermo, Italy \\ ${ }^{6}$ Institute of Pathology, Università di Palermo, Palermo, Italy
}

To prospectively evaluate the prognostic significance of TP53, $\mathrm{H}-, \mathrm{K}-$-, and N-Ras mutations, DNA-ploidy and S-phase fraction (SPF) in patients affected by locally advanced laryngeal squamous cell carcinoma (LSCC). Eight-one patients (median follow-up was 71 months) who underwent resective surgery for primary operable locally advanced LSCC were analyzed. Tumor DNA was screened for mutational analysis by PCR/SSCP and sequencing. DNA-ploidy and SPF were performed by flow cytometric analyses. Thirty-six patients (44\%) had, at least, a mutation in the TP53 gene. Of them, 22\% (8/36) had double mutations and 3\% (1/36) had triple mutations. In total, 46 TP53 mutations were observed. The majority (41\%) of these occur in exon 5 (19/46), while the mutations in exons 6,7 , and 8 were represented in 14,7 , and 6 patients, respectively (31\%, 15\%, and 16\%). Five LSCC patients (6\%) showed a mutation in $\mathrm{H}$-Ras gene. Sixty-three percent of the cases (51/81) were DNA aneuploidy, $14 \%$ of these $(7 / 51)$ were multiclonal. Thirty-nine patients (48\%) had an high SPF value. At Univariate analysis, the DNA aneuploidy, high SPF (>15.1\%), TP53 mutations and, in particular, the mutations that occur in exons 5 and 8 were significantly related to quicker disease relapse and short OS. At Multivariate analysis, the major significant predictors for both disease relapse and death were high SPF and any TP53 mutations. While histological grade G3 was an independent factor only for relapse. In conclusions, any TP53 mutations and high SPF are important biological indicators to predict the outcome of LSCC patients. J. Cell. Physiol. 206: 181-188, 2006. @ 2005 Wiley-Liss, Inc.

The tumor of the larynx is a rare form of neoplasia representing $2 \%$ of all human tumors. From $90 \%$ to $95 \%$ of such cancers are laryngeal squamous cell carcinomas (LSCC) (Rizos et al., 1999); incidence varies according to geographical area and most probably depends on specific environmental risk factors (Parkin et al., 1993). With regard to their site of origin, LSCCs may show a variable disease course and furthermore, tumors with exactly the same clinical and histological features may have a different clinical outcome. This indicates that traditional clinicopathological staging based only on the TNM system and on histological grading may not be sufficient for an accurate identification of patients at high-risk for disease recurrence or death (Goldsmith and Pillsbury, 1991; Tomasino et al., 1996). Published data report that highly-proliferative tumors (high Sphase fraction evaluated by flow cytometry) with aneuploid DNA cell content are more aggressive (Merkel and McGuire, 1990; Tomasino et al., 1995). Whereas, the prognostic value of DNA ploidy has been clearly established for other types of solid tumors (Ross, 1993), its role in LSCCs is still controversial. Moreover, certain molecular events leading to carcinogenesis of the larynx are still not fully understood. Several protoncogens and oncosuppressors would seem to be targets for risk factors, for example, tobacco, excessive alcohol, exposure to certain environmental carcinogens such as asbestos, all commonly associated with the development of LSCCs (Ronchetti et al., 2004). Until now, no welldefined genetic model of LSCC progression has been identified. However, it has been proposed a model where genetic alterations of oncogens and oncosuppressors are involved in the early phases, and in the promotion and progression of laryngeal cancer (Califano et al., 2000). Furthermore, it is probably the accumulation of such genetic alterations and not necessarily their order, which brings about progression. Nevertheless, mutations of the oncosuppressor TP53 would seem to represent an early event in the development of head and neck cancers.

Several reports have shown that mutations of TP53 are present in about $50 \%$ of solid tumors, although the frequency of such mutations varies according to the type of tumor involved (Chang et al., 1993; Levine et al., 1994;

Abbreviations: SPF, S-phase fraction; LSCC, laryngeal squamous cell carcinoma; PCR, polymerase chain reaction; SSCP, single strand conformation polymorphism; AJCC, American Joint Committee on Cancer; DFS, disease-free survival; OS, overall survival; SCCHN, squamous cell carcinomas of the head and neck.

Antonio Russo and Simona Corsale have contributed equally to this work.

*Correspondence to: Antonio Russo, Via Veneto 5, 90144 Palermo, Italy. E-mail: lab-oncobiologia@usa.net

Received 15 March 2005; Accepted 15 April 2005

DOI: $10.1002 /$ jep. 20447 
Soussi et al., 1994). Data regarding the mutation rate in LSCCs are discordant. In human tumors there is often the loss of both TP53 alleles and whereas the first one may show puntiform mutations, the second allele may be lost during tumor progression. Most of the TP53 mutations have been found in exons 5-8; many of these may lead to the formation of a protein able to alter its bond with the DNA and which has a longer average lifespan resulting in cell accumulation.

Data regarding the frequency of mutations in genes of the Ras family (H-K-N-Ras) in patients with LSCCs are also discordant. Most of the mutations of these three genes are found in codons 12 and 13, and some, but fewer, in codon 61 . In any case, mutations in these genes always lead to the expression of a constitutionally active proteic product.

Further information on the role of oncogene and oncosuppressor alterations and their proteic products might be useful for the identification of new factors aimed at the diagnosis and treatment of LSCCs. The aim of our study was to analyze in 81 cases of locally advanced LSCCs, the mutational status of TP53 and of the Ras family genes, by means of PCR-SSCP and sequencing, the status of DNA ploidy and SPF, by means flow cytometric technique, to establish their association with traditional clinicopathological variables and to determine their possible prognostic value.

\section{MATERIALS AND METHODS} Study design

A prospective study was performed on paired tumor and normal laryngeal tissue samples from a consecutive series of 81 patients of which 60 in stage III and 21 in stage IV undergoing potentially radical surgical resection for primary tumor of larynx at a single institution (Department of Oncology, University of Palermo, Palermo, Italy) between April 1990 and December 1998. Briefly, the following inclusion criteria were used: (a) electively resected primary LSCC, (b) processing of fresh paired normal mucosa-tumor samples within $30 \mathrm{~min}$ after tumor removal. In order to avoid evaluator variability in the patients, all resection specimens and microscopic slides were meticulously examined by two independent pathologists (R.M.T. and V.M.) who were not aware of the original diagnosis and of the results of the molecular analysis. The complete excision of the primary tumor was histologically proven by examination of the resected margins. All tumors were histologically confirmed to be squamous cell carcinomas. In addition, the pathologists assessed tumor site (supraglottis, glottis, subglottis), tumor size, pathological stage, tumor grade (histological differentiation), and the presence or absence of lymph node metastases. Tumors were staged according to the American Joint Committee on Cancer (AJCC) and graded as well (G1), moderately (G2), and poorly (G3) differentiated. Lymph node involvement was evaluated clinically and histologically without considering the number or location of nodes. Written informed consent was obtained from all patients included in this study. Information on survival (disease-free survival-DFS-and overall survival-OS) was obtained directly from clinical charts and through the Oncology Section at our Institution. Clinicopathological, and research variables and follow-up data of all patients have been recorded prospectively in a computerized registry database.

Postoperatively, all patients were checked at 3-monthly intervals for the first 2 years, at 6-monthly intervals for the next 2 years, and annually thereafter. The follow-up program included a clinical examination, blood tests (including CEA and SCC assays), and annual chest X-ray. Disease relapse (local recurrence or distant metastases) was confirmed histologically where possible.

\section{Tissue handling and DNA extraction}

Multiple samples (4 to 8 ) of the primary tumor tissue were taken from at least four different tumor areas (including the core and the invasive edge of the tumor). The portion of primary tumor was obtained by superficial biopsy of either the tumor bulk or the edge of the malignant ulcer for more infiltrative cancer. All tissues were carefully trimmed to remove as much non-neoplastic tissue as possible, avoiding the non-viable areas. Furthermore, samples of normal mucosa (as confirmed by histology) were taken from a macroscopically uninvolved area $2-5 \mathrm{~cm}$ away from the tumor site, to be used as control for biomolecular and flow cytometric analysis. The tissues were bisected, one-half of each sample was processed for pathological examination, and the remaining half of the sample pool was immediately frozen and stored at $-80^{\circ} \mathrm{C}$ until analyzed. The adequacy of the material was checked on frozen tissue sections and only tissue samples with more than $80 \%$ tumor content were utilized in subsequent biomolecular and flow-cytometric analyses. Where present, areas with a high content of nonneoplastic cells were removed from the frozen block with a scalpel. Evaluation of each biomolecular variable (genetic status of TP53 and H- K- N-Ras, DNA-ploidy, and S-phase fraction) was performed independently by researchers who had no knowledge of the clinical data regarding the samples. Genomic DNA was extracted using the QIAamp Tissue Kit (Qiagen, Hilden, Germany) with the standard protocol from primary LSCC and normal laryngeal specimens.

\section{Detection of TP53 and H- K- N-Ras gene mutations}

Mutations within the $H-K-N$-Ras and TP53 genes were detected by SSCP analysis following PCR amplification of the exon 1 for H- K-Ras, exons 1-2 for N-Ras, and of the exons 58 for TP53, respectively (Table 1), performed as previously described (Bazan et al., 2002a; Russo et al., 2002) controls were amplified by PCR and included in the experiment. In all PCR assays, aerosol-resistant pipette tips were used to avoid crosscontamination. The quality and the concentration of the amplification products were verified by $1.5 \%$ agarose gel electrophoresis and ethidium bromide staining. One-hundred nanogram aliquots of the amplified DNA fragments, purified and concentrated by filtration through Microcon 50 columns (Amicon, Beverly, MA) were denatured and analyzed by SSCP analysis. PCR-SSCP analysis was repeated twice for each sample to minimize the possibility of artifacts due to

TABLE 1. PCR primers used for PCR and SSCP analyses of p53, H-, K-, N-Ras genes

\begin{tabular}{|c|c|c|c|}
\hline & Primers: sense $5^{\prime} \rightarrow 3^{\prime}$ & Primers: antisense $5^{\prime} \rightarrow 3^{\prime}$ & Anneal, ${ }^{\circ} \mathrm{C}$ \\
\hline \multicolumn{4}{|l|}{ P53 } \\
\hline Exon 5 & TTCCTCTTCCTACAGTAGTC & CGATGGTGAGCAGCTGGG & $58^{\circ}$ \\
\hline Exon 6 & CGATGGTGAGCAGCTGGG & ATGGCAAAACCAGACCTCAG & $50^{\circ}$ \\
\hline Exon 7 & TGTGTTATCTCCTAGGTTGG & TGGCAAGTGGCTCCTGAC & 58 \\
\hline Exon 8 & TCCTATCCTGAGTAGTGGT & TCCTGCTTGCTTACCTCG & $54^{\circ}$ \\
\hline \multicolumn{4}{|l|}{ H-Ras } \\
\hline Exon 1 & GACGGAATATAAGCTGGTGG & TAACTACCCCTCTGCACGGA & $58^{\circ}$ \\
\hline K-Ras & & & \\
\hline Exon 1 & $\begin{array}{l}\text { GTGTGACATGTTCTAATA- } \\
\text { TAGTGACA }\end{array}$ & GAATGGTCCTGCACCAGTAA & $58^{\circ}$ \\
\hline \multicolumn{4}{|c|}{ 1月UTCACA } \\
\hline Exon 1 & GACTGAGTACAAACTGGTGG & CTCTATGGTGGGATCATATT & $54^{\circ}$ \\
\hline Exon 2 & GGTGAAACCTGTTTGTTGGA & ATACACAGAGGAAGCCTTCG & $54^{\circ}$ \\
\hline
\end{tabular}


contamination or polymerase errors and interpretation of SSCP analysis was performed by consensus of two investigators. DNA of normal mucosa from each patient was also amplified and run in parallel with matched tumoral DNA samples on SSCP gels, to evaluate the occurrence of germ line mutations or polymorphisms. Individual ssDNA fragments with shifted mobilities, compared to normal control, were electroeluted from polyacrylamide gel, as described previously (La Farina et al., 1998), reamplified and sequenced. Automated sequencing was performed using the Big Dye Terminator Cycle Sequencing Kit (Applied Biosystem, Foster City, CA) and the model 3100A Genetic Analyzer (Applied Biosystem).

\section{Cellular DNA content and S-phase fraction (SPF) flow cytometric analyses}

DNA flow cytometry was performed on mechanically disaggregated samples of frozen tumor tissue to determine DNA-ploidy, DNA index, and S-phase fraction (SPF) as previously reported (Russo et al., 1994). Briefly, healthy laryngeal mucosa was used as an internal DNA-diploid control for each sample. Tumors with DI $=1$ were defined as DNA-diploid and those with lower or higher DI values were considered DNAaneuploid if they contained $>10 \%$ aneuploid cells. DNA aneuploidy results were further subdivided into monoploid (with only one aneuploid peak) and multiploid (with two or more aneuploid peaks).

\section{Statistical analysis}

Association between biological and clinicopathological variables was evaluated by means of the Chi-square test and, where appropriate, Yates' correction. DFS was measured from the day of primary surgery to the date of first relapse (locoregional or metastatic) and OS from the day of surgery to the day of death specifically due to the LSCC. If patients did not relapse or die, they were censored at the time of their last follow-up. Clinical and morphobiological variables were examined by means of the Kaplan-Meier method; significance of differences for each prognostic factor was assessed by the logrank and Wilcoxon tests or trend tests, where appropriate. Multivariate analysis was carried out by means of Cox proportional hazards model, using a backward procedure (Cox, 1972). $P$ values less than 0.05 were considered statistically significant.

\section{RESULTS \\ Clinicopathologic variables}

The majority (98\%) of patients affect by locally advanced LSCC are males (79/81) while only $2 \%$ of patients are female (2/81) (Table 2). Sixteen patients (20\%) are less than 60 years old, $40(49 \%)$ of them are from 60 to 69 years old, while $25(31 \%)$ are more than 69 . The median age is 66 years (range 44-85). Forty-eight patients $(59 \%)$ showed a tumor in glottis, 29/81 (36\%) in supraglottis, and 4/81 (5\%) in subglottis. Twenty-four patients $(30 \%)$ had a stage IV tumor while, the others, 57 patients $(70 \%)$ have a stage III tumors. In addition, these series included $60(74 \%)$ tumors limited to the larynx with vocal cord fixation while 21 (26\%) have an extension beyond confines of larynx. Assessment of the grade of differentiation of the tumor showed that there were 20/81 (25\%) well- (G1), 47/81 (58\%) moderately(G2), and 14/81 (17\%) poorly-differentiated LSCC. Node status was known for all patients, with 21/81 (26\%) being node positive and 60/81 (74\%) being node negative.

\section{Mutation analysis of the Ras genes family (H- K- N-Ras)}

Mutation analysis of exon 1 of the $\mathrm{H}$ - K-Ras genes and exons 1-2 of N-Ras gene were performed on genomic DNA from locally advanced LSCC of 81 patients by the PCR-SSCP technique. Aberrantly migrating bands were found in $6 \%(5 / 81)$ of the cases. All samples have mutations in H-Ras gene. Unfortunately, it was not
TABLE 2. Patient characteristics $(n=1)$

\begin{tabular}{lc}
\hline & No. of patients \\
\hline Sex & 79 \\
Male & 2 \\
Female & \\
Age (yr) & 16 \\
$\quad<60$ & 40 \\
$60-69$ & 25 \\
Z70 & \\
Tumor site & 29 \\
Supraglottis & 48 \\
Glottis & 4 \\
Subglottis & \\
Node status & 60 \\
Negative & 21 \\
Positive & \\
Size & 60 \\
T3 & 21 \\
T4 & \\
Stage & 57 \\
III & 24 \\
IV & \\
Tumor grade & 20 \\
G1 & 47 \\
G2 & 14 \\
G3 &
\end{tabular}

possible to establish the exact site and nature of the genetic alterations in 5 of the 81 patients because the frozen material and mutated DNA were no longer available. No other mutation was found in the other genes of Ras family (N-, K-Ras).

\section{Mutation analysis of the TP53 gene}

Mutation analysis of exons 5 to 8 of the TP53 gene was performed on genomic DNA from locally advanced LSCC of 81 patients by the PCR-SSCP technique. Aberrantly migrating bands were found in $44 \%(36 / 81)$ of the cases (Fig. 1). Sequence analysis of the DNA fragments with altered electrophoretic mobility made it possible to establish the exact site and nature of the genetic alteration in 18 tumor samples. Overall, 46 TP53 mutations were identified in 36 of the 81 screened LSCCs, and sequence data were obtained for 21 . The features of the TP53 mutations are summarized in Table 3. Of the 46 mutations, $41 \%$ (19 of 46 ) were in exon $5,31 \%$ (14 of 46 ) in exon $6,15 \%$ ( 7 of 46 ) in exon 7 , and $13 \%$ ( 6 of 46$)$ in exon 8. Nine tumor samples were found to harbor two (eight in two exons) or three (one in three exons) different TP53 mutations. Three of the 21 sequenced mutations (14\%) were found to be frameshifts ( 2 microdeletions and 1 microinsertions), whereas 18 (86\%) were singlenucleotide substitutions. Sixty-one percent of the latter were missense (11 of 18), 39 were silent ( 7 of 18) mutations, while were not found any nonsense mutations. Moreover, transitions $(61 \%, 11$ of 18) were far more frequent than transversions $(31 \%, 7$ of 18). The 21 mutations identified spanned 14 codons, interesting all of the TP53 mutations in exon 6 occur in codon 213 . No germ line mutations were found indicating that in every case the change was somatic. Twenty-nine percent of the mutations (6 of 21) occurred in conserved domains (areas II-V). In addition, by taking into account the specific functional and structural domains of TP53 affected by the mutations, the mutations were classified as follows: $2 / 21$ cases (9\%) with mutations of the L2, 3/21 cases $(14 \%)$ with mutations of the $\mathrm{LSH}$ motif, and $1 / 21$ cases $(5 \%)$ with mutations of the L3. Since silent mutations do not determine any aminoacid change in the protein, they have been included in wild-type group for statistical analysis. 

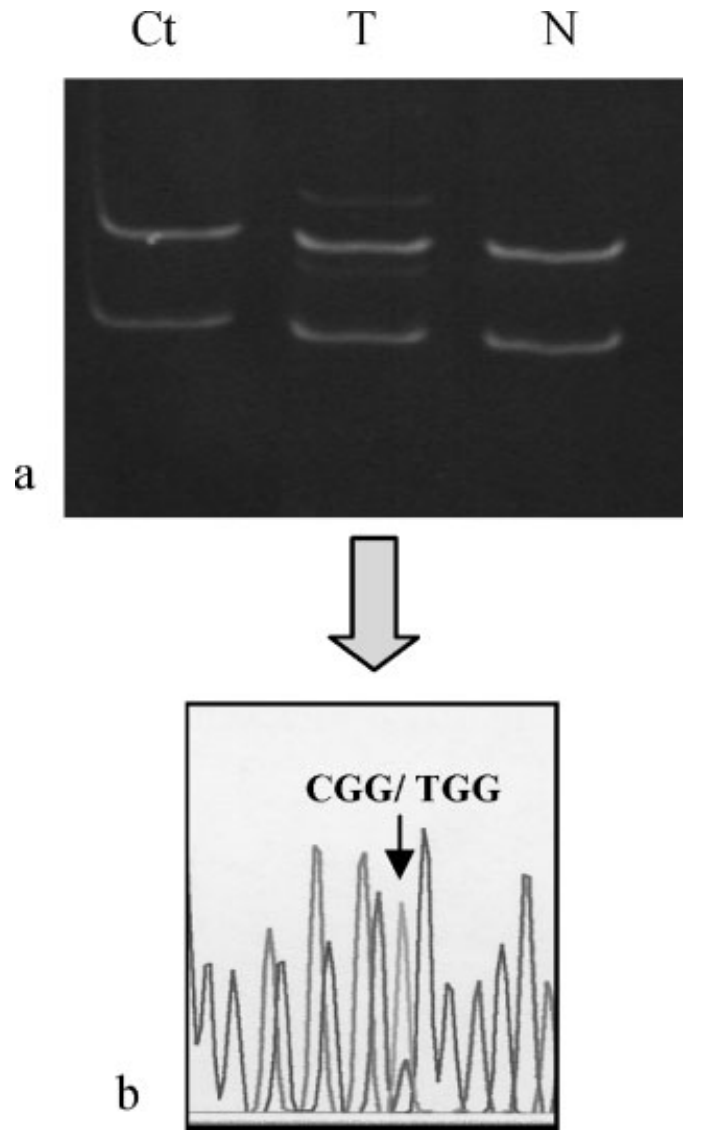

Fig. 1. SSCP analysis of exon 8 of the $p 53$ gene amplified from laryngeal squamous cell carcinomas (LSCC) and normal-appearing tissue genomic DNA of one patient (case 827). The tumor DNA is at the left (T) and the normal tissue DNA (N) is at the right (a). The extra bands visualized by arrows in line 2 correspond to ssDNA molecules harboring mutations in codon 282 (CGG to TGG) as confirmed by sequencing (b).

\section{Cellular DNA content and S-phase evaluation}

Adequate DNA histograms were obtained for all normal and tumoral tissues by means of flow cytometry. The coefficients of variation of the DNA-diploid peaks ranged from $2.5 \%$ to $4.8 \%$ (median $3.4 \%$ ). DNA aneu- ploidy was found in $63 \%$ of the cases (51/81), and $14 \%$ of these (7/51) showed multiclonality. The SPF ranged from $3.2 \%$ to $38 \%$ (median: $15.1 \%$ and interquartile range: $7.1 \%-20.6 \%$ ). The median SPF of DNA-aneuploid tumors was $18.6 \%$ while that of the DNA-diploid tumors was $6.8 \%(P<0.01)$. By using the SPF median value as cut-off point, tumors were accordingly divided into low (=15.1) and high (>15.1) SPF tumors.

\section{Relationship between biomolecular indicators and clinical data}

No significant relationship was seen between the clinicopathological and biological variables analyzed (data not shown).

\section{General outcome}

The median follow-up time in our study group was 71 months (range 11-137 months). At the time of this report, 45/81 patients had relapsed, of which 33 had distant metastases and 12 locoregional recurrence, while $41 / 81$ had died for tumor related causes. The median survival of the whole group was 69 months and the survival at 5 years was $52.8 \%$.

\section{Uni- and Multivariate analysis of prognostic factors}

At univariate analysis, presence of lymph node metastases, tumor grade G3, DNA-aneuploidy, high SPF ( $>15.1 \%)$, any TP53 mutations (Table 4$)$, and the type of TP53 mutations (mutations in exon 5 vs. mutations in exons $6-8$ or mutations in exon 8 vs. mutations in exons 5-7) (data not shown) proved to be significantly related to quicker relapse and shorter overall survival. Figure 2 shows the probability of DFS (a) and OS (b) according to TP53 mutations. The limited number of cases mutated in H-Ras, does not permit to enclose a statistical analysis. The significant variables at univariate analysis were entered in a multivariate logistic regression model with backward elimination. At multivariate analysis, high S-phase and any TP53 mutations were independent prognostic factors, both for disease recurrence and for survival, while advanced histological grade was only predictive of the former (Table 5). Furthermore, when only exon 5 mutations and not any TP53 mutations were considered, they proved to be prognostically independent variable both for disease

TABLE 3. List of 21 p53 characterized mutations in 18 patients with LSCCs

\begin{tabular}{|c|c|c|c|c|c|c|c|}
\hline Sample & Mutated exon & Mutated codon & $\begin{array}{l}\text { Nucleotide } \\
\text { change }\end{array}$ & $\begin{array}{c}\text { Aminoacid } \\
\text { change }\end{array}$ & Type mutation & CD & $\mathrm{Zn}-\mathrm{BD}$ \\
\hline 261 & 5 & $159-160$ & $\mathrm{GCCATG} \rightarrow$ GTG & - & Frameshift & $\mathrm{N}$ & - \\
\hline 335 & 6 & 213 & $\mathrm{CGA} \rightarrow \mathrm{CGG}$ & $\mathrm{Arg} \rightarrow \mathrm{A} 0 \mathrm{rg}$ & Missense & $\mathrm{N}$ & - \\
\hline 383 & 7 & 248 & $\mathrm{CGG} \rightarrow \mathrm{TGG}$ & Arg $\rightarrow \operatorname{Trp}$ & Missense & $\mathrm{Y}$ & L3 \\
\hline 402 & 7 & 278 & $\mathrm{GAA} \rightarrow \mathrm{GCAA}$ & - & Frameshift & $\mathrm{Y}$ & $\mathrm{LSH}$ \\
\hline 419 & 5 & 179 & $\mathrm{CAT} \rightarrow \mathrm{TAT}$ & $\mathrm{His} \rightarrow \mathrm{Tyr}$ & Missense & $\mathrm{Y}$ & L2 \\
\hline \multirow[t]{2}{*}{484} & 5 & 151 & $\mathrm{CCC} \rightarrow \mathrm{CT}$ & - & Frameshift & $\mathrm{N}$ & - \\
\hline & 6 & 213 & $\mathrm{CGA} \rightarrow \mathrm{CGG}$ & Arg $\rightarrow$ Arg & Missense & $\mathrm{N}$ & - \\
\hline 511 & 5 & 157 & $\mathrm{GTC} \rightarrow \mathrm{TTC}$ & $\mathrm{Val} \rightarrow \mathrm{Phe}$ & Missense & $\mathrm{N}$ & - \\
\hline 671 & 7 & 265 & $\mathrm{GGC} \rightarrow \mathrm{TGC}$ & Gly $\rightarrow$ Cys & Missense & $\mathrm{N}$ & - \\
\hline 765 & 6 & 213 & $\mathrm{CGA} \rightarrow \mathrm{CGG}$ & $\mathrm{Arg} \rightarrow \mathrm{Arg}$ & Missense & $\mathrm{N}$ & - \\
\hline \multirow[t]{2}{*}{788} & 5 & 184 & $\mathrm{GAT} \rightarrow \mathrm{AAT}$ & Asp $\rightarrow$ Asn & Missense & $\mathrm{N}$ & L2 \\
\hline & 6 & 213 & $\mathrm{CGA} \rightarrow \mathrm{CGG}$ & Arg $\rightarrow$ Arg & Missense & $\mathrm{N}$ & - \\
\hline 798 & 6 & 213 & $\mathrm{CGA} \rightarrow \mathrm{CGG}$ & $\mathrm{Arg} \rightarrow \mathrm{Arg}$ & Missense & $\mathrm{N}$ & - \\
\hline 827 & 8 & 282 & $\mathrm{CGG} \rightarrow \mathrm{TGG}$ & Arg $\rightarrow$ Trp & Missense & $\mathrm{Y}$ & LSH \\
\hline 829 & 5 & 137 & $\mathrm{CTG} \rightarrow \mathrm{CAG}$ & Leu $\rightarrow$ Gln & Missense & $\mathrm{Y}$ & - \\
\hline \multirow[t]{2}{*}{832} & 5 & 151 & $\mathrm{CCC} \rightarrow \mathrm{CAC}$ & Pro $\rightarrow \mathrm{His}$ & Missense & $\mathrm{N}$ & - \\
\hline & 7 & 249 & $\mathrm{AGG} \rightarrow \mathrm{ACG}$ & $\mathrm{Arg} \rightarrow \mathrm{Thr}$ & Missense & $\mathrm{N}$ & - \\
\hline 840 & 7 & 245 & $\mathrm{GGC} \rightarrow \mathrm{TGC}$ & Gly $\rightarrow$ Cys & Missense & $\mathrm{N}$ & - \\
\hline 993 & 8 & 280 & $\mathrm{AGA} \rightarrow \mathrm{ACA}$ & Arg $\rightarrow$ Thr & Missense & $\mathrm{Y}$ & $\mathrm{LSH}$ \\
\hline 1027 & 6 & 213 & $\mathrm{CGA} \rightarrow \mathrm{CGG}$ & Arg $\rightarrow$ Arg & Missense & $\mathrm{N}$ & - \\
\hline 1036 & 6 & 213 & $\mathrm{CGA} \rightarrow \mathrm{CGG}$ & Arg $\rightarrow$ Arg & Missense & $\mathrm{N}$ & - \\
\hline
\end{tabular}


TABLE 4. DFS and OS of the LSCCs patient according to clinicopathologic variables

\begin{tabular}{|c|c|c|c|c|c|c|}
\hline & \multicolumn{3}{|c|}{ DFS } & \multicolumn{3}{|c|}{ OS } \\
\hline & No. of patients & OR $(95 \% \mathrm{CI})$ & $P$ & No. of patients & OR $(95 \% \mathrm{CI})$ & $P$ \\
\hline Total ptatiens & 81 & & & 81 & & \\
\hline \multicolumn{7}{|l|}{ Tumor grade } \\
\hline G1 & 20 & 1.00 & & 20 & 1.00 & \\
\hline $\mathrm{G} 2$ & 47 & $2.07(0.90-4.75)$ & n.s. & 47 & $1.91(0.83-4.41)$ & n.s. \\
\hline G3 & 14 & $3.70(1.40-9.79)$ & 0.008 & 14 & $2.58(0.93-7.13)$ & 0.068 \\
\hline \multicolumn{7}{|l|}{ Node status } \\
\hline Negative & 60 & 1.00 & & 60 & 1.00 & \\
\hline Positive & 21 & $2.82(1.41-5.64)$ & 0.003 & 21 & $2.57(1.25-5.27)$ & 0.018 \\
\hline \multicolumn{7}{|l|}{ DNA-ploidy status ${ }^{a}$} \\
\hline Diploid & 30 & 1.00 & & 30 & 1.00 & \\
\hline Aneuploid monoclonal & 44 & $3.18(1.54-6.56)$ & 0.002 & 44 & $2.60(1.25-5.43)$ & 0.011 \\
\hline Aneuploid multiclonal & 7 & $5.47(1.97-15.3)$ & 0.003 & 7 & $4.07(1.37-12.1)$ & 0.011 \\
\hline \multicolumn{7}{|l|}{$\mathrm{SPF}^{\mathrm{b}}$} \\
\hline$\leq 15.1 \%$ & 40 & 1.00 & & 40 & 1.00 & \\
\hline$>15.1 \%$ & 39 & $3.80(1.99-7.26)$ & $<0.001$ & 39 & $2.88(1.49-5.57)$ & 0.002 \\
\hline \multicolumn{7}{|l|}{$\mathrm{p} 53^{\mathrm{c}}$} \\
\hline No mutations & 45 & 1.00 & & 45 & 1.00 & \\
\hline Any mutations & 36 & $2.11(1.16-3.83)$ & 0.014 & 36 & $2.75(1.45-5.21)$ & 0.002 \\
\hline
\end{tabular}

${ }^{\mathrm{a} A l l}$ DNA-aneuploid subgroups are compared with patients with DNA-diploid tumors.

${ }^{\mathrm{b}}$ All high SPF subgroups are compared with patients with low SPF tumors.

${ }^{\mathrm{c}}$ All mutation subgroups are compared with patients with no mutations (wild-type p53).
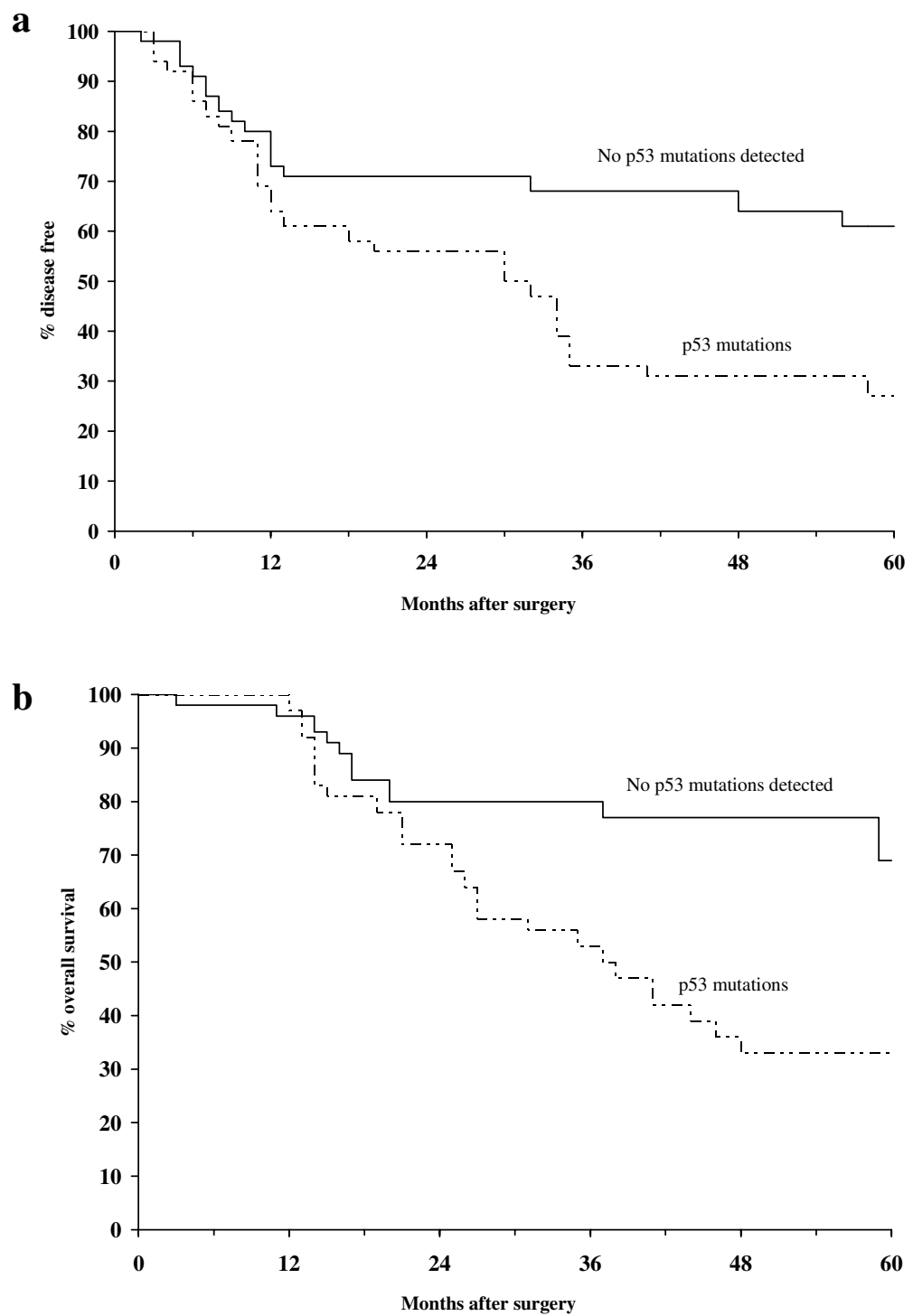

Fig. 2. DFS (a) and OS (b) of 81 patients with LSCC according to p53 mutations. 
TABLE 5. Cox proportional hazards analysis to predict the HR of relapse or death in LSCC patients

\begin{tabular}{lcccr}
\hline & \multicolumn{2}{c}{ Relapse $(\mathrm{N}=81)$} & Death $(\mathrm{N}=81)$ \\
\cline { 2 - 5 } & HR $(95 \% \mathrm{CI})$ & $P$ & HR (95\% CI) & $P$ \\
\hline $\begin{array}{l}\text { Tumor grade } \\
\text { G3 versus G1 }\end{array}$ & $3.56(1.33-9.55)$ & 0.011 & & \\
$\begin{array}{l}\text { SPF } \\
\quad>15.1 \% \text { versus } \leq 15.1 \%\end{array}$ & $4.00(2.07-7.73)$ & $<0.001$ & $3.10(1.58-6.10)$ & 0.001 \\
p53 Any mutation versus no & $2.07(1.11-3.85)$ & 0.023 & $3.05(1.57-5.91)$ & $<0.001$ \\
$\quad$ & & & & \\
$\quad$ mutation
\end{tabular}

recurrence and for survival, while exon 8 mutations were only predictive of the latter (data not shown).

\section{DISCUSSION}

The classification of epithelial hyperplastic lesions of the larynx is based, principally, on the progression of their histological features to LSCC. Although so far there has been no clear definition of a genetic model for LSCC progression, it would appear that it depends on an accumulation of genetic alterations (Califano et al., 1996). The most frequent events regard alterations of the gene TP53, which seem to be present in the early phase of the development of LSCCs. Several studies have reported that TP53 mutations bring about the loss of normal protein function, resulting in genomic instability and the occurrence of gross genomic abnormalities (Dowell and Hall, 1995; Ko and Prives, 1996; Levine, 1997; Lane, 1999; Prives and Hall, 1999; Somasundaram, 2000). Since TP53 mutations are an early event, therefore, further genomic alterations are necessary for the progression of the hyperplastic lesion into a clear carcinoma.

Previous analyses performed by several researchers on different types of tumors have shown that most of the TP53 mutations affect exons 5-8, which code for residues $130-286$, the most important region for the folding and the stabilization of the tertiary structure of the protein, and which contains the site-specific, DNAbinding domain (Cho et al., 1994). Mutations outside exons 5-8 are rarely found and include mutations occurring within the introns of the splicing sites, which appear to bring about aberrant RNA splicing. In this study, performed on 81 patients with locally advanced LSCCs, we found a mutation rate of $57 \%$ (46/81), which is higher than that reported in literature for LSCCs at the same stage $(30 \%-50 \%)(\mathrm{Li}, 1995$; Sarkar et al., 1996; Golusinski et al., 1997; Alsner et al., 2001). Several factors might be responsible for this variability, for example, the presence of silent mutations, the heterogeneity of tumors and also the different methods used for identifying the mutations and for storing samples. There is no doubt that disease stage is an important factor with regard to the TP53 mutation rate. Several reports, in fact, have shown that TP53 mutations have been found in early lesions and that their frequency appears to increase in carcinomas at more advanced stages (Dolcetti et al., 1992; Maestro et al., 1992; Anwar et al., 1993a; Boag et al., 1993; Boyle et al., 1993; Chung et al., 1993; Field et al., 1993; Nadal and Cardesa, 2003). Nine tumor samples were found to harbor more than one TP53 mutations; for our experience, it may establish that these mutations origins from a multiclonal tumor but only the use of more accurate techniques, such us Laser Microdissection, may throw light upon this investigation (Bazan et al., 2005).
Several studies have reported that the TP53 exons most commonly mutated depend on the geographical area involved. In the USA, in fact, such mutations usually regard exon 7 (Brachman et al., 1992), in Japan, exons 5 and 8 (Sakai and Tsuchida, 1992), and in the United Kingdom exon 4 (Field et al., 1993). In our own study most of the mutations occurred in exon 5. Even if the number of cases presented in this study is limited, we propose that environmental factors could be fundamental in the development of larynx tumors. The presence of different mutations might depend on specific local carcinogens, which possibly interact with more common factors, such as alcohol and tobacco, predisposing to a multistep process that leads to epithelial larynx tumorigenesis.

Furthermore, it seems that the Ras family genes play an exceptional part in laryngeal carcinogenesis. Although literature has reported a high mutational rate in laryngeal carcinoma (Anwar et al., 1993b), such results have not been confirmed for LSCCs (Fracchiolla et al., 1995; Rizos et al., 1999). In our own cases of locally advance LSCCs, we found a mutational rate of $6 \%(5 / 81)$ in the gene $\mathrm{H}$-Ras and none at all in $\mathrm{K}$ - and N-Ras. These results agree with those of previous studies reporting a low mutational rate in squamous cell carcinomas of the head and neck (SCCHN) of subjects of the Western world (Fracchiolla et al., 1995; Kiaris and Spandidos, 1995; Rizos et al., 1999). The difference in Ras gene mutations in the various studies may be due to geographical differences, which might modify the effect of exposure to specific environmental risk factors (Fracchiolla et al., 1995; Rizos et al., 1999). Our results, therefore, have confirmed that the Ras oncogens do not seem to be implicated in the carcinogenesis of LSCCs. On the other hand, it appears that in such tumors the main activation mechanism of Ras genes is their aberrant expression, which probably depends not on mutations of the first codifying exon, but on alterations of the gene promoter, an instability of the Ras gene chromosome carriers resulting in genic amplification (McDonald et al., 1994; Kiaris et al., 1995).

Furthermore, although DNA-ploidy and SPF evaluated by flow cytometry, continue to be used in many types of tumors for the prediction of the clinical outcome of the disease, their function has still not been clearly defined in cases of LSCCs.

The difference in published reports might depend on sampling and storing methods (fresh, frozen, paraffinembedded). In our own study, although DNA aneuploidy and high S-phase did not prove to be linked to any of the clinicopathological and biological variables examined, it may well be that the genomic instability caused by the alteration or loss of function of TP53 gave rise to a selection of highly proliferative aneuploid clones. In advanced tumors, the accumulation of alterations in 
the oncogens, oncosuppressors, and genes involved in the maintenance of genomic integrity might make the tumoral mass deriving from such clones particularly resistant to treatment, resulting in a worse clinical outcome. (Russo et al., 1995).

Although TP53 gene alterations are commonly found in head and neck cancers, their prognostic value in LSCCs has not been clearly established. Our report showed that any TP53 mutations and high SPF are strong prognostic indicators of both disease recurrence and survival in patients with locally advanced LSCCs. These findings also show that TP53 gene status and SPF maintain their predictive role even the presence of established traditional prognostic variables such as tumor site, node status, size, and histological grade. Our investigation confirms and reinforce previous studies on the prognostic role of TP53 alterations and high SPF. Some studies in fact showed that TP53 overexpression is an independent prognostic factor for disease-free and overall survival in primary and advanced LSCCs (Hirvikoski et al., 1997; Jin et al., 1998; Jackel et al., 2001). Moreover some studies identified high SPF as an important biological indicator in LSCCs (Tomasino et al., 1995). Although it is not yet clear how the evaluation of the TP53 mutation status associated or not with cell proliferation should be inserted in the choice of theraupetic management of locally advanced LSCCs these biological indicators might provide information and rational basis to develop more specific clinical treatment for this group of patients.

It may well be that not all TP53 mutations are functionally equal. Such mutations, in fact, might be divided into two groups. The first involves the mutations responsible for structural anomalies, which might destabilize the tertiary structure of the protein and bring about loss of binding capacity to DNA. The second group regards mutations leading to an alteration of amino acid residues, which interact with the DNA, eliminating crucial contact with the latter (Iniesta et al., 1998). Depending on the location of a TP53 mutation, therefore, the suppressive functions or clinical outcome may or may not be affected (Chomchai et al., 1999). Some alterations could lead to a nuclear p53 protein accumulation detected by immunohistochemistry (IHC); some mutations could lead to the production of a truncated protein, or to a protein with a C-terminal aminoacid sequence very different from that of the wild-type, may not cause its stabilization and consequent accumulation (Bazan et al., 2002b).

For these reasons, IHC and mutational analysis of p53 appear to be complementary rather than equivalent methods of investigation to assess the occurrence of alterations in this key regulator of cell proliferation, genetic stability, and apoptosis.

In conclusion, in our study it has been observed a strong association between TP53 mutations and an unfavorable prognosis, both with regard to higher risk of disease recurrence and to death, in patients affected by locally advanced LSCCs. If our results are confirmed by large prospective studies, it will be possible to considere such patients as suitable candidates for alternative treatment strategies directed against tumors with mutated TP53.

\section{LITERATURE CITED}

Alsner J, Sorensen SB, Overgaard J. 2001. TP53 mutation is related to poor prognosis after radiotherapy, but not surgery, in squamous cell carcinoma of the head and neck. Radiother Oncol 59(29):179-185.

Anwar K, Nakakuki K, Imai H, Naiki H, Inuzuka M. 1993a. Over-expression of p53 protein in human laryngeal carcinoma. Int J Cancer 53(6):952-956.
Anwar K, Nakakuki K, Naiki H, Inuzuka M. 1993b. Ras gene mutations and HPV infection are common in human laryngeal carcinoma. Int J Cancer 53(1): $22-28$.

Bazan V, Zanna I, Migliavacca M, Sanz-Casla MT, Maestro ML, Corsale S, Macaluso M, Dardanoni G, Restivo S, Quintela PL, Bernaldez R, Salerno S, Morello V, Tomasino RM, Gebbia N, Russo A. 2002a. Prognostic significance of p16INK4a alterations and 9p21 loss of heterozygosity in locally advanced laryngeal squamous cell carcinoma. J Cell Physiol 192(3):286-293

Bazan V, Migliavacca M, Tubiolo C, Macaluso M, Zanna I, Corsale S, Amato A Calò V, Dardanoni G, Morello V, La Farina M, Albanese I, Tomasino RM, Gebbia N, Russo A. 2002b. Have p53 gene mutations and protein expression a different biological significance in colorectal cancer? J Cell Physiol 191:237246 .

Bazan V, La Rocca G, Corsale S, Agnese V, Macaluso M, Migliavacca M, Gregorio V, Cascio S, Sisto PS, Di Fede G, Buscemi M, Fiorentino E, Passantino R, Morello V, Tomasino RM, Russo A. 2005. Laser pressure catapulting (LPC) Optimization LPC-system and genotyping of colorectal carcinomas. J Cell Physiol 202(2):503-509.

Boag G, Lee CS, Charalambous D, Rode J. 1993. p53 expression in laryngeal carcinoma. Pathology 25(4):394-397.

Boyle JO, Hakim J, Koch W, van der Riet P, Hruban RH, Roa RA, Correo R Eby YJ, Ruppert JM, Sidransky D. 1993. The incidence of p53 mutations increases with progression of head and neck cancer. Cancer Res 53(19):44774480.

Brachman DG, Graves D, Vokes E, Beckett M, Haraf D, Montag A, Dunphy E, Mick R, Yandell D, Weichselbaum RR. 1992. Occurrence of p53 gene deletions and human papilloma virus infection in human head and neck cancer. Cancer Res 52(17):4832-4836.

Califano J, van der Riet P, Westra W, Nawroz H, Clayman G, Piantadosi S, Corio R, Lee D, Greenberg B, Koch W, Sidransky D. 1996. Genetic progression mode for head and neck cancer: Implications for field cancerization. Cancer Res 56(11):2488-2492.

Califano J, Westra WH, Meininger G, Corio R, Koch WM, Sidransky D. 2000. Genetic progression and clonal relationship of recurrent premalignant head and neck lesions. Clin Cancer Res 6(2):347-352.

Chang F, Syrjanen S, Kurvinen K, Syrjanen K. 1993. The p53 tumor suppressor gene as a common cellular target in human carcinogenesis. Am J Gastroenterol 88(2):174-186

Cho Y, Gorina S, Jeffrey PD, Pavletich NP. 1994. Crystal structure of a p53 tumor suppressor-DNA complex: Understanding tumorigenic mutations. Science 265(5170):346-355.

Chomchai JS, Du W, Sarkar FH, Li YW, Jacobs JR, Ensley JF, Sakr W, Yoo GH. 1999. Prognostic significance of p53 gene mutations in laryngeal cancer. Laryngoscope 109(3):455-459.

Chung KY, Mukhopadhyay T, Kim J, Casson A, Ro JY, Goepfert H, Hong WK Roth JA. 1993. Discordant p53 gene mutations in primary head and neck cancers and corresponding second primary cancers of the upper aerodigestive tract. Cancer Res 53(7):1676-1683.

Cox D. 1972. Regression models and life tables. J Am Stat Assoc 34:187-220.

Dolcetti R, Doglioni C, Maestro R, Gasparotto D, Barman L, Pastore A, Romanelli M, Baiocchi M. 1992. p53 over-expression is an early event in the development of human squamous-cell carcinoma of the larynx: Genetic and prognostic implications. Int J Cancer 52(2):178-182.

Dowell SP, Hall PA. 1995. The p53 tumour suppressor gene and tumour prognosis: Is there a relationship? J Pathol 177(3):221-224.

Field JK, Pavelic ZP, Spandidos DA, Stambrook PJ, Jones AS, Gluckman JL. 1993. The role of the p53 tumor suppressor gene in squamous cell carcinoma of the head and neck. Arch Otolaryngol Head Neck Surg 119(10):11181122

Fracchiolla NS, Pignataro L, Capaccio P, Trecca D, Boletini A, Ottaviani A, Poll E, Maiolo AT, Neri A. 1995. Multiple genetic lesions in laryngeal squamous cell carcinomas. Cancer 75(6):1292-1301.

Goldsmith MM, Pillsbury HC. 1991. Pathologic and cytometric indicators of biologic behaviour in laryngeal cancer. In: Silver CE, editor. Laryngeal cancer. New York: Thieme Medical Publisher pp 27-32.

Golusinski W, Olofsson J, Szmeja Z, Szyfter K, Szyfter W, Biczysko W, Hemminki K. 1997. Alteration of p53 gene structure and function in laryngeal squamous cell cancer. Eur Arch Otorhinolaryngol 254 Suppl 1:S133-S137.

Hirvikoski P, Kumpulainen E, Virtaniemi J, Johansson R, Haapasalo $H$ Marin S, Halonen P, Helin H, Raitiola H, Pukander J, KellokumpuLehtinen P, Kosma VM. 1997. p53 expression and cell proliferation as prognostic factors in laryngeal squamous cell carcinoma. J Clin Oncol 15(9):31113120

Iniesta P, Vega FJ, Caldes T, Massa M, de Juan C, Cerdan FJ, Sanchez A, Lopez JA, Torres AJ, Balibrea JL, Benito M. 1998. p53 exon 7 mutations as a predictor of poor prognosis in patients with colorectal cancer. Cancer Lett 130(1-2):153160

Jackel MC, Sellmann L, Youssef S, Dorudian MA, Fuzesi L. 2001. Prognostic significance of expression of p53, bcl-2 and bax in squamous epithelial carcinoma of the larynx-a multivariate analysis. HNO 49(3):204211.

Jin YT, Kayser S, Kemp BL, Ordonez NG, Tucker SL, Clayman GL, Goepfert H Luna MA, Batsakis JG, El-Naggar AK. 1998. The prognostic significance of the biomarkers p21WAF1/CIP1, p53, and bcl-2 in laryngeal squamous cel carcinoma. Cancer 82(11):2159-2165.

Kiaris H, Spandidos DA. 1995. Analysis of H-ras, K-ras and N-ras genes expression, mutation and amplification in laryngeal tumours. Int $\mathrm{J}$ Oncol 7 : $75-80$.

Kiaris H, Spandidos DA, Jones AS, Vaughan ED, Field JK. 1995. Mutations, expression and genomic instability of the H-ras proto-oncogene in squamous cell carcinomas of the head and neck. Br J Cancer 72(1):123-128.

Ko LJ, Prives C. 1996. p53: Puzzle and paradigm. Genes Dev 10(9):10541072

La Farina M, Maturi N, Stira S, Russo A, Bazan V, Albanese I. 1998. Direct identification of each specific mutation in codon 12 and 13 of ci-ki-ras2 by SSCP analysis. Biochem Biophys Res Commun 246(3):813-815.

Lane DP. 1999. Exploiting the p53 pathway for cancer diagnosis and therapy. Br J Cancer 80 Suppl 1:1-15. 
Levine AJ. 1997. p53, the cellular gatekeeper for growth and division. Cell 88(3): $323-331$

Levine AJ, Perry ME, Chang A, Silver A, Dittmer D, Wu M, Welsh D. 1994. The 1993 Walter Hubert Lecture: The role of the p53 tumour-suppressor gene in tumorigenesis. Br J Cancer 69(3):409-416.

Li Y. 1995. Relationship between mutation of p53 gene and malignant level of squamous carcinoma in the larynx. Zhonghua Er Bi Yan Hou Ke Za Zhi 30(2):101-104.

Maestro R, Dolcetti R, Gasparotto D, Doglioni C, Pelucchi S, Barzan L, Grandi E, Boiocchi M. 1992. High frequency of p53 gene alterations associated with protein overexpression in human squamous cell carcinoma of the larynx. Oncogene 7(6): 1159-1166.

McDonald JS, Jones H, Pavelic ZP, Pavelic LJ, Stambrook PJ, Gluckman JL 1994. Immunohistochemical detection of the H-ras, K-ras, and N-ras oncogene in squamous cell carcinoma of the head and neck. J Oral Pathol Med 23(8):342346.

Merkel DE, McGuire WL. 1990. Ploidy, proliferative activity and prognosis. DNA flow cytometry of solid tumors. Cancer 65(5):1194-1205.

Nadal A, Cardesa A. 2003. Molecular biology of laryngeal squamous cell carcinoma. Virchows Arch 442(1):1-7.

Parkin DM, Pisani P, Ferlay J. 1993. Estimates of the worldwide incidence of eighteen major cancers in 1985. Int J Cancer 54(4):594-606.

Prives C, Hall PA. 1999. The p53 pathway. J Pathol 187(1):112-126.

Rizos E, Sourvinos G, Arvanitis DA, Velegrakis G, Spandidos DA. 1999. Low incidence of $\mathrm{H}$-, $\mathrm{K}$ - and $\mathrm{N}$-ras oncogene mutations in cytological specimens of laryngeal tumours. Oral Oncol 35(6):561-563.

Ronchetti D, Neglia CB, Cesana BM, Carboni N, Neri A, Pruneti G, Pignataro L 2004. Association between p53 gene mutations and tobacco and alcoho exposure in laryngeal squamous cell carcinoma. Arch Otolaryngol Head Neck Surg 130(3):303-306.

Ross DW. 1993. Clinical usefulness of DNA ploidy and cell cycle studies. Arch Pathol Lab Med 117(11):1077.
Russo A, Bazan V, Morello V, Tralongo V, Nagar C, Nuara RB, Dardanoni G, Bazan P, Tomasino RM. 1994. Vimentin expression, proliferating cell nuclear antigen and flow cytometric factors. Prognostic role in breast cancer. Anal Quant Cytol Histol 16(5):365-374.

Russo A, Bazan V, Gebbia N, Pizzolanti G, Tumminello FM, Dardanoni G, Ingria F, Restivo S, Tomasino RM, Leto G. 1995. Flow cytometric DNA analysis and lysosomal cathepsins B and L in locally advanced laryngeal cancer. Relation ship with clinicopathologic parameters and prognostic significance. Cancer 76(10): $1757-1764$

Russo A, Migliavacca M, Zanna I, Valerio MR, Latteri MA, Grassi N, Pantuso G, Salerno S, Dardanoni G, Albanese I, La Farina M, Tomasino RM, Gebbia N, Bazan V. 2002. p53 mutations in L3-loop zinc-binding domain, DNA-ploidy, and $S$ phase fraction are independent prognostic indicators in colorectal cancer: A prospective study with a five-year follow-up. Cancer Epidemiol Biomarker Prev 11(11):1322-1331.

Sakai E, Tsuchida N. 1992. Most human squamous cell carcinomas in the ora cavity contain mutated p53 tumor-suppressor genes. Oncogene 7(5):927933.

Sarkar FH, Sakr WA, Li YW, Jacobs J, Crissman JD. 1996. Tumor suppresso p53 gene mutation in squamous cell carcinoma of the larynx. Diagn Mol Pathol 5(3):201-205

Somasundaram K. 2000. Tumor suppressor p53: Regulation and function. Fron Biosci 5:D424-D437.

Soussi T, Legros Y, Lubin R, Ory K, Schlichtholz B. 1994. Multifactorial analysis of p53 alteration in human cancer: A review. Int $J$ Cancer 57(1):1-9.

Tomasino RM, Daniele E, Bazan V, Morello V, Tralongo V, Nuara R, Nagar C, Salvato M, Ingria F, Restivo S, Dardanoni G, Vecchione A, Russo A. 1995 Prognostic significance of cell kinetics in laryngeal squamous cell carcinoma: Clinicopathological associations. Cancer Res 55(24):6103-6108.

Tomasino RM, Bazan V, Daniele E, Nuara R, Morello V, Tralongo V, Leto G Russo A. 1996. Biological characterization of laryngeal squamous-cell carci noma. Anticancer Res 16(4B):2257-2267. 